\title{
Engineered Natural Geosorbents for In-Situ Immobilization of DNAPLs and Heavy Metals
}

\author{
Walter J. Weber \\ University of Michigan \\ Suite 181 EWRE Building \\ Ann Arbor, MI 48109-2125
}

\section{Research Progress}

The report summarizes work progress from 9/15/02-12/31/2003 for the project. Progresses in five specific areas of investigation are summarized below. 1. Production of engineered natural geosorbents (ENGs) An innovative technology has been developed for effecting rapid diagenesis-like transformations in geologically young NOM to produce more condensed materials that are capable of effectively sorbing organic contaminants from environmental systems. A number of natural organic materials, i.e., a sphagnum moss peat (MI peat), oak leaves, green ash leaves, red maple leaves, pine bark, corn stalk and soybean stalk, were treated using liquid-phase water at superheated temperatures and pressures in batch reactors under an inert atmosphere. Conditions for the treatment were optimized in terms of temperature, time, moisture content, and catalyst addition. The physicochemical properties and sorption capacities of ENGs for DNAPL and heavy metals were characterized. 2. Characterization of the physicochemical properties of ENGs Significant changes in the physicochemical properties of treated organic materials were observed in terms of surface area, surface morphology, elemental composition and molecular structures. Surface area measurements revealed that MI peat samples treated at $50 \mathrm{oC}$ and $100 \mathrm{oC}$ have essentially the same surface area as the original peat ( $\sim .55 \mathrm{~m} 2 / \mathrm{g})$, but an order of magnitude increase then occurred at $150 \mathrm{oC}$, followed by a gradual decline to a level about four-fold greater than that of the untreated peat (i.e., $\sim 2.2 \mathrm{~m} 2 / \mathrm{g}$ ) at $300 \mathrm{oC}$. Elemental composition analyses showed that carbon and nitrogen contents were found to increase linearly, while oxygen and nitrogen contents decreased linearly when temperatures increased from $50 \mathrm{oC}$ to $200 \mathrm{oC}$ or $300 \mathrm{oC}$. The atomic ratios of hydrogen to carbon $(\mathrm{H} / \mathrm{C})$ and oxygen to carbon $(\mathrm{O} / \mathrm{C})$ decreased linearly as temperature increased. The results are consistent with increasing degrees of geochemical maturation as increasing treatment temperatures. The functional group characters of the treated and untreated materials were examined by FTIR and 13C-NMR. For example, FTIR spectra of MI peat shows that bonded -OH group and $\mathrm{H}$ bonds in the region of 3440-3400 cm-1 increased when the MI peat was treated at $50 \mathrm{oC}$, then decreased from $100 \mathrm{oC}$ to $300 \mathrm{oC}$ comparing with that of original raw peat. Aliphatic groups in the region of $2930-2850 \mathrm{~cm}-1$ did not change too much from $50 \mathrm{oC}$ and $100 \mathrm{oC}$, and they increased from $150 \mathrm{oC}$ to $300 \mathrm{oC}$, which indicated symmetric and asymmetric $\mathrm{C}-\mathrm{H}$ stretching vibrations in aliphatic $\mathrm{CH}, \mathrm{CH} 2$, and $\mathrm{CH} 3$ groups. Benzene rings in the region of $1630-1590 \mathrm{~cm}-1, \mathrm{~N}-\mathrm{H}$ bond in the region of 1520-1510 cm-1, ester and expoxide in the region of 1275-1245 cm-1 were increased when treatment temperatures increased from $50 \mathrm{oC}$ to $300 \mathrm{oC}$. The NMR spectra of MI peat samples show that alkyl C and aromatic C significantly increased when temperature increased from 50-250oC, while carbohydrate C, carboxyl C and carbonyl C decreased. The results of these analyses clearly show diagenetic-like transformation of the treated materials with increasing temperatures of the liquid-water phase used for treatment. Peat samples treated at 250oC had similar 13C-NMR spectra. The hydrophobicity index $(\mathrm{IH})$ and aromaticity index (IAr) were calculated for MI peat samples. IH and IAr increased from 0.831 to 4.19 and from 0.71 to 1.18 , respectively, with increasing treatment temperatures. 3 .

Characterization of the sorption and desorption properties of ENGs for TCE, PCE The sorption/desorption properties of the modified natural organic materials were examined with respect to tetrachloroethylene (PCE) and trichloroethylene (TCE), two major components of DNAPLs. Initial tests to examine the sorption and desorption behaviors were conducted by batch tests with adding fixed amount of treated and untreated organic materials, i.e., corn stalk, soybean stalks, oak leaves, red maple leaves, green ash leaves and pine bark, to aqueous solutions containing PCE. The results showed that significantly greater amount of the PCE was sorbed by treated materials than by untreated raw materials. Sorption capacities of pine bark, corn stalk and soybean stalk were increased up to 13.5 times after they were treated with superheated water at $200 \mathrm{oC}$. Desorption was greatly decreased for treated materials. Complete isotherms for sorption and desorption of TCE by MI peat samples treated at temperatures ranging from $50 \mathrm{oC}$ to $300 \mathrm{oC}$ for five hrs were determined. The results show that the equilibrium sorption and desorption data fitted very well with 
Freundlich model. Values of Freundlich unit-capacity coefficient (KF) are observed to increase with increasing treatment temperature and isotherm nonlinearity (n) decreased with increased temperatures of treatment for both sorption and desorption. Strong correlations are observed between values of KF and $n$ and treatment temperatures and atomic ratios of oxygen and carbon $(\mathrm{O} / \mathrm{C})$ with correlation coefficients $(\mathrm{R} 2)$ ranging from 0.841 to 0.983 . The sorption and desorption isotherms of PCE by treated MI peat were also determined. The sorption capacities of MI peat for PCE were also increased with increasing treatment temperatures. The sorption and desorption of TCE in the presence and absence of the competing PCE and 1,2-dichlorbenzene (1,2-DCB) were also examined for treated and untreated MI peat samples. The sorption and desorption data for TCE are still fitted well with the Freundlich isotherm model in the presence of the competing solutes. Both PCE and 1,2-DCB were found to greatly depress TCE sorption, with PCE having greater effects than DCB, presumably because the molecular structure of the former is more similar to that of TCE. The nonlinearity of sorption and desorption isotherms of TCE increased in the presence of PCE and 1,2-DCB. 4. Characterization of the sorption and desorption properties of ENGs for heavy metals 4a. Selections of test organic materials for sorption of metals A number of organic materials, i.e., MI old peat, MI young peat, WA peat, corn stalk, soybean stalk, oak leaves, green ash leaves, and pine needle, were selected to measure their sorption capacities for heavy metals. Cadmium was chosen as a representative of heavy metals. The sorption capacities of these materials for $\mathrm{Cd} 2+$ were determined by batch tests at one fixed solid and liquid ratio. The results showed that the selected organic materials had very strong sorption for $\mathrm{Cd} 2+$, although their sorption capacities varied greatly among the test materials. MI old peat had highest sorption capacity with a Cd2+ concentration of 57207.2ug/g solid and corn stalk had lowest sorption capacity with a $\mathrm{Cd} 2+$ concentration of $23421.7 \mathrm{ug} / \mathrm{g}$ among the test materials. Their distribution coefficients, i.e., Koc, was calculated by divided Cd2+ concentrations in solid phase (qe) with its aqueous phase concentrations $(\mathrm{Ce})$ at equilibrium $(\mathrm{Koc}=\mathrm{qe} / \mathrm{Ce})$, also varied greatly among the tested organic materials, ranging from 347.8 to 2783.4 . The sorbed $\mathrm{Cd} 2+$ was strongly attached to the sorbent materials with only 3.03 to $28.7 \%$ of $\mathrm{Cd} 2+$ desorbed. Their desorption Koc values were 5.6-8.5 times higher than that of sorption. 4b. Effect of engineering treatment on sorption capacities of natural organic sorbents for metals Although the above organic materials had high sorption capacities for heavy metals, their sorption capacities for organic compounds, e.g., TCE and phenanthrene, were not very high and sorbed organic compounds are easily desorbed from those sorbent materials. Our results from this project have showed that the sorption capacities of natural organic materials for organic compounds increased significantly, while the desorption of sorbed compounds was remarkably decreased after those natural organic materials were treated by superheated water alone. However, their sorption capacities for heavy metals were decreased after treatment. For example, the sorption capacities of MI old peat for cadmium did not change too much after it was treated with superheated water from $100 \mathrm{oC}$ to $150 \mathrm{oC}$, then decreased sharply from $200 \mathrm{oC}$ to $300 \mathrm{oC}$. The possible major sorption mechanism of natural organic materials for heavy metals is ion-exchange from their functional groups, such as carboxyl and phenolic groups. At high temperatures, these functional groups are reduced or eliminated and their sorption capacities for metals therefore are also reduced. It would have great application potentials if the engineered natural geosorbents have strong sorption capacities for both organic contaminants and heavy metals. A number of oxidants and other chemicals were added to reactors for treating MI old peat, MI young peat, pine needle, and soybean stalk using superheated water at $200 \mathrm{oc}$ or $250 \mathrm{oC}$. Their sorption capacities for cadmium were determined by batch studies. The results showed that MI old peat still had very strong sorption capacity for cadmium when it was treated using superheated water at 250oC with Na4P2O7. However, its sorption capacities were significantly reduced when it was treated by superheated water only or superheated water with $\mathrm{ZnCl} 2$ or Fe2O3. For MI young peat treated by superheated water with $\mathrm{Na} 4 \mathrm{P} 2 \mathrm{O} 7$ or $\mathrm{KMnO} 4$, pine needle treated with Na4P2O7, soybean stalk treated with (NH4)2S2O8, their sorption capacities for cadmium increased or kept almost same as their raw materials with cadmium concentrations in solid phase increased from 40426.1ug/g to 47491.0 or $45685.9 u g / g$ for MI young peat, from 28137.9ug/g to 42089.6ug/g for pine needle, and from $37097.9 \mathrm{ug} / \mathrm{g}$ to $40051.8 \mathrm{ug} / \mathrm{g}$ for soybean stalk. The isotherms of sorption and desorption of those materials for cadmium were also determined for treated and untreated MI peat, pine needle and soybean stalk. The Langmuir isotherm model was used for analyses of the equilibrium sorption and desorption data of cadmium. The results suggested that sorption and desorption of cadmium by MI young peat, pine needle and soybean stalk treated at different conditions fit well with the Langmuir model. Related model parameters sorption and desorption are calculated and values of maximum sorption capacities (qm) were very large ranging from $18181.82 \mathrm{ug} / \mathrm{g}$ to $58823.53 \mathrm{ug} / \mathrm{g}$ for sorption and from 15082.96ug/g to 71123.76ug/g. 4c. Sorption rates of ENGs for metals Sorption rates for uptake of cadmium 
by treated and untreated MI young peat, pine needle and soybean stalk samples were also determined. The quantity of cadmium sorbed at time t was determined from a mass balance between the concentrations in solution initially and at time t. The sorption rate data of these materials were fitted well by a pseudosecond-order rate model yielding R2 values greater than 0.993 . Sorption for cadmium by the tested organic sorbents was found to be very rapid and reached equilibrium in around two (2) hours. The rate constant values of $\mathrm{k}$ were generally increased for treated samples with oxidants. $4 \mathrm{~d}$. Effect of $\mathrm{pH}$, ion strength and sorbent mass The effects of $\mathrm{pH}$, ion strength and mass amount on the sorption and desorption of cadmium by treated and untreated organic materials were also determined. MI young peat and pine needle were exposed to Cd(NO3)2 solution with $0.01 \mathrm{M}$ NaNO3 as background and their pHs were adjusted using $1 \mathrm{~N}$ $\mathrm{HNO} 3$ or $\mathrm{NaOH}$. The results showed that uptake of cadmium by both treated and untreated MI young peat and pine needle increased when $\mathrm{pH}$ of solution increased from 2.0 to 7.0 . At $\mathrm{pH} 2.0$, less than $3 \%$ or $1 \%$ of cadmium was sorbed by MI young peat or pine needle and their sorption reached their maximum at $\mathrm{pH} 7.0$ for both materials, then decreased when $\mathrm{pH}$ increased to 8.0. However, their desorption from both treated and untreated MI young peat and pine needle was decreased when $\mathrm{pH}$ increased from 2.0 to 8.0. At $\mathrm{pH} 2.0$, $71.8 \%$ and $85.6 \%$ of sorbed cadmium were desorbed from raw and treated MI young peat, while $93 \%$ and $90.7 \%$ of sorbed cadmium were desorbed from raw and treated pine needle. When $\mathrm{pH}$ reached from 5.5 to 8.0, the desorption of both peat and pine needle did not change too much, ranging from $10 \%$ to $25 \%$. The effect of ion strength of solution on the sorption and desorption of cadmium by treated and untreated MI young peat and pine needle were also determined. Ground organic materials were mixed with $\mathrm{Cd}(\mathrm{NO} 3) 2$ solution with NaNO3 concentrations ranging from 0, 0.005, 0.01, 0.1 and $0.5 \mathrm{M}$ for 2 days to determine sorption and desorption of cadmium. The results showed that both materials had high sorption and lowest desorption for cadmium in Mili-Q water. When ion strength increased, cadmium sorption decreased and desorption increased and they were more evident when NaNO3 concentrations increased to $0.1 \mathrm{M}$. In $0.1 \mathrm{M}$ NaNO3 solution, treated MI young peat sorbed much more cadmium than raw peat, i.e., $47.9 \%$ vs $6.7 \%$. Treated pine needle (28.2\%) also sorbed much more cadmium than raw pine needle (3.9\%) from $0.1 \mathrm{M}$ NaNO3 solution. For desorption, almost $100 \%$ of sorbed cadmium were desorbed from raw MI young peat in $0.1 \mathrm{M}$ and $0.5 \mathrm{M}$ NaNO3 solution, while only $42.1 \%$ and $59.7 \%$ of sorbed cadmium were desorbed from treated peat. Similar results were found for pine needle. The effect of sorbent mass on the sorption and desorption of cadmium by treated and untreated pine needle and soybean stalk from aqueous solution were also investigated. Different amounts of the tested organic materials were added to test tubes containing $\mathrm{Cd}(\mathrm{NO} 3) 2$ in $0.01 \mathrm{M} \mathrm{NaNO3}$ solution for 2 days to measure sorption and desorption of cadmium by treated and untreated soybean stalk and pine needle. Cadmium concentrations in the sorbents were much higher at the lower sorbent amount, i.e., 25 and $75 \mathrm{mg}$, for both soybean stalk and pine needle, then decreased when sorbent amount increased till $150 \mathrm{mg}$ of sorbents, and level off at $175 \mathrm{mg}$. Both treated soybean stalk and pine needle took up more cadmium than their raw materials. It is not surprise that total sorption percentage increased and desorption of cadmium from both soybean stalk and pine needle decreased with increasing sorbent amount. More sorbed cadmium was desorbed from untreated soybean stalk (6.64-32.7\%) and pine needle (33.5-75.5\%) than from treated soybean stalk (2.73-27.2\%) and pine needle (26.5 - 33.0\%). 5. Characterization of the competitive sorption and desorption properties of ENGs for DNAPL and heavy metals Combined sorption and desorption of DNAPLs and heavy metals by treated and untreated organic sorbents were investigated for this study. Sorption and desorption isotherms of 1,2-DCB by treated and untreated pine needle were determined with and without presence of cadmium (100 ppm). The results showed that sorption and desorption isotherms of 1,2-DCB were still fitted well with Freundlich model with coefficients (R2) greater than 0.988 (for sorption) and 0.967 (desorption). In the presence of cadmium, 1,2-DCB sorption were decreased for both treated and untreated pine needle indicating there was a competing sorption between 1,2-DCB and cadmium. Treated pine needle had higher sorption capacities for $1,2-\mathrm{DCB}$ than its raw materials. Sorption and desorption isotherms of cadmium by treated and untreated pine needle were also determined with and without presence of 1,2-DCB. Sorption and desorption data of cadmium were fitted well to Langmuir isotherm model with coefficients (R2) greater than 0.978 (for sorption) and 0.950 (desorption). In the presence of 1,2-DCB, sorption of cadmium were reduced more for treated pine needle, but not for raw pine needle. This might be due treated pine needle had high sorption for 1,2-DCB than raw pine needle. When cadmium concentrations increased in the solution, the sorption of1,2DCB was decreased. 